\title{
High School Students’ Attitudes Associated with Biotechnology and Molecular Genetics Concepts in Brazil ${ }^{*}$
}

\author{
Alexandre de Sá Freire, Márcia Cristina Fernandes Xavier, Milton Ozório Moraes \\ Genetic Epidemiology and Functional Genomics Research Group Oswaldo Cruz Institute, \\ Oswaldo Cruz Foundation, Rio de Janeiro, Brazil \\ Email:mmoraes@fiocruz.br
}

Received September $3^{\text {rd }}$, 2012; revised October $7^{\text {th }}$, 2012; accepted October $18^{\text {th }}$, 2012

\begin{abstract}
There is an enormous gap between scientific production and scientific education in Genetics and Biotechnology concerning stem cells, transgenics, genetically engineered medicines and so on. In order to investigate the knowledge and the perception of these concepts among teenagers, a total of 334 surveys were distributed to high school students in one private and two state schools in the Rio de Janeiro state, Brazil. Interviews were also used as a qualitative tool to assess the validity of the data obtained in the surveys. Students reported clear ideas about transgenics, but not about genetic engineering of recombinant medication or genomics. The results suggest that when issues are discussed, instead of being explained, they are better assimilated by students, and that association of information in the press with school classes may help to spread scientific concepts.
\end{abstract}

Keywords: Science Teaching; Biotechnology; Opinion; Genetics; Molecular Biology; DNA

\section{Introduction}

Since the rise of recombinant DNA technology, molecular genetics has grown considerably. Terms like molecular biology and biotechnology have become more frequently used by the media and, therefore, became part of everyday life. Such development uncovers new issues such as diagnostic tests based on DNA detection, the use of DNA testing for paternity and transgenic food development. These themes are escalating fast enough to create a huge gap between these new discoveries and the average information discussed in class. Although the media attempts to fill in this gap by reporting scientific discoveries and technological innovations, it frequently fails to provide correct information (Eyck, 2005; Massarani \& Moreira, 2005). In addition, such development is not properly discussed in high school biology classes.

Dawson and Schibeci (2003) have thrown light on the need of teaching students about the recent technological discoveries. The authors said that "we need to prepare students to make personal and social choices about issues related to Science and Technology". Cavanagh et al. (2005) indicate that efforts in scientific education are still necessary, showing that a significant portion of high school students do not know about Biotechnology. In this context, Jay Lemke (1990) points out that the science learning process is related to necessity of learning the science language, i.e., as students learn scientific concepts, they learn to speak the scientific language.

As a methodological approach, high school students from both state and private schools were submitted to a survey in order to assess their background knowledge. Results show that students have limited view not only about concepts in basic Genetics, but also in relation to new Biotechological innovations. Results point out that science and technology education has not been correctly addressed.

\section{Methodology}

\section{Design}

High school students from one private and two state schools, all located in the State of Rio de Janeiro, in the cities of Petrópolis and Angra dos Reis (with more than 150,000 inhabitants) participated in this study. All students were in the third year of high school and most of them (2 out 3 classes) did not take formal genetics classes.

We used quantitative and qualitative approaches complementarily. In a first approach, students' attitudes were evaluated by a quantitative survey and, secondly, interviews were conducted and recorded in order to clarify students’ opinions.

\section{Quantitative Approach: The Survey}

The quantitative approach was performed through a survey. A total of 337 students answered the survey. Among these students, 198 were from Colégio Estadual D. Pedro II, 105 from Colégio Estadual Arthur Vargas (two State schools in Petrópolis and Angra dos Reis, respectively) and 34 students from Colégio Dom Bosco, a private school in Angra dos Reis. All students were 16 - 18 years/old irrespective of the school they attended. No gender bias was observed and our studied population had $55 \%$ of boys. It is important to notice that, in Brazil, private schools are generally from middle, higher classes, while public schools people from lower classes are more prevalent.

The issues in the survey included transgenics, genetic improvement, genetically modified organisms (GMOs), human cloning, stem cells, Genome Project, genetic therapy, molecular diagnosis, paternity tests, and genetic vaccines. The survey was constructed with two sets of questions. In the first set, students were asked to answer whether they agreed with (A), disagreed with (D) or had neutral opinion (N) about issues concerning Biotechnology, including their general acceptance, application, 
benefits and risks to society. The second set included five "yes"/"no" questions with room for students to give examples of Biotechnological improvement.

\section{Statistical Analyses}

In order to assess the consistency of answers from the first set of questions when compared to the second one, we analyzed the joint distribution of the data from the two sets of questions by creating $2 \times 2$ contingency tables. The statistical significance of the cross tabulations was measured by Chi-square tests considering the significance level of $p<0.05$ (Graphpad Instat $6.0)$.

\section{Qualitative Approach}

Answers to the surveys have provided important information, but raised some inconsistencies which we tried to resolve through semi-structured interviews. These interviews allowed in-depth exploration and granted flexibility for students to express themselves freely and solve ambiguities.

These interviews were in the number of three and were carried out with three groups of students, each one from a different class with five, six and eight students, respectively. The interviews were carried out in a lower class students' state school. First, there were four girls and just one boy. At the second, there were three boys and three girls. In the last interview, there were three boys and five girls. Students were between 17 and 18 years old and came from lower classes. Interviews were recorded and fully transcribed. We used key sentences to represent the students' general view on each subject.

\section{Results}

We assumed that students' opinions could be influenced by their socioeconomical condition, since students from private schools are generally from high-income families, while students from state schools usually come from low-income families. In comparing both contexts, scientific education and access to the internet and to laboratories vary significantly. This factor may have influenced the opinions obtained in this study. To prevent this bias, analyses were performed separately and as there was not significant variation between the two contexts, high-income and low-income students (data not shown), and results here embody all students:

Answers for the first set of questions of the survey are presented in Table 1. In some cases, students showed clear opinions. For instance, $62 \%$ of the students did not agree with human cloning for biotechnological social improvement, but, in relation to DNA paternity tests, most of the students (82\%) agreed with their use. Diagnostic tests based on DNA technology were considered acceptable for $58 \%$ of the students. Other results, such as Genetic Therapy, Genetically Modified Organisms, stem cells and Genetic Vaccines had a "neutral" rate of around $40 \%$.

The "yes" and "no" answers to the second block of questions are presented in Table 2. The majority of the students reported that they have not eaten transgenic food (76\%), while $65 \%$ showed to have no restrictions to eating transgenics, and $63 \%$ said they had no restriction about the application of genetically engineered medicine. Nevertheless, $79 \%$ of the students believe that the results of the Genome Project make the prognosis of cancer possible.
Table 1.

Answers for the first set of questions on the survey.

\begin{tabular}{lcccc}
\hline \multicolumn{5}{c}{ Students opinion } \\
\hline \multicolumn{1}{c}{ Biotech advance } & $\mathrm{A}$ & $\mathrm{D}$ & $\mathrm{N}$ & Total \\
\hline Transgenics & $156(47 \%)$ & $80(24 \%)$ & $93(29 \%)$ & 329 \\
Genetic improvement & $228(69 \%)$ & $31(9 \%)$ & $71(22 \%)$ & 330 \\
GMO & $152(46 \%)$ & $52(16 \%)$ & $124(38 \%)$ & 328 \\
Human cloning & $73(22 \%)$ & $206(62 \%)$ & $51(16 \%)$ & 330 \\
Stem cells & $178(55 \%)$ & $22(7 \%)$ & $126(39 \%)$ & 326 \\
Genome project & $187(56 \%)$ & $34(10 \%)$ & $110(33 \%)$ & 331 \\
Genetic therapy & $159(49 \%)$ & $37(11 \%)$ & $131(40 \%)$ & 327 \\
DNA diagnostic tests & $176(59 \%)$ & $29(10 \%)$ & $94(31 \%)$ & 299 \\
DNA paternity test & $270(82 \%)$ & $13(4 \%)$ & $44(14 \%)$ & 327 \\
Genetic vaccines & $174(53 \%)$ & $34(10 \%)$ & $122(37 \%)$ & 330 \\
\hline
\end{tabular}

A—agree; D—disagree; $\mathrm{N}$-neutral.

Table 2.

Answers to "yes" or "no" questions regarding the issues in everyday situations.

\begin{tabular}{lccc}
\hline \multicolumn{1}{c}{ Questions } & & & \\
\hline & Yes & No & Total \\
Have you eaten & 79 & 248 & 327 \\
transgenic food? (1) & $(24 \%)$ & $(76 \%)$ & \\
Do you have restrictions to & 110 & 206 & 316 \\
eating transgenic food? (2) & $(35 \%)$ & $(65 \%)$ & \\
Have you ever used any & 18 & 311 & 329 \\
genetically engineered medicine? (3) & $(5 \%)$ & $(95 \%)$ & \\
Would you have any restriction & 121 & 209 & 330 \\
in using genetically engineered medicine? (4) & $(37 \%)$ & $(63 \%)$ & \\
Is it possible to perform cancer prognosis & 257 & 69 & 326 \\
tests using data from Genome Projects? (5) & $(79 \%)$ & $(21 \%)$ & \\
\hline
\end{tabular}

Table 3 shows contingency tables created to evaluate the coherence of the answers collected in the two sets of questions, (Table 3). These data show that, for some issues, students' attitudes are consistent as tested by the statistical analysis. For example, the comparison of students' opinions about restrictions to the use of transgenic food ("yes" or "no" questions) and the acceptability of this product as a biotechnological advance showed a significant number of students with no restrictions; they also agreed with the usefulness and benefits of this kind of food ( $p$-value $<0.001$ ). The opposite association is also true, meaning that students with restrictions to eating transgenic food do not agree with their social benefits. In addition, students that found diagnostic tests based on DNA technology to be a social and health improvement for society also stated that access to data from the human Genome Project facilitates the development of diagnostic tests for cancer $(p$-value $<0.01)$.

After evaluating the qualitative data obtained from the interviews, it became clear that some students had restrictions to the use of transgenic food, and that they were aware of the risks to the environment, supporting their views about this issue in the survey. Also, they showed more consistent knowledge of the theme. Some of their opinions indicate that they continually argue about the potential harm of transgenic food and would prefer that their use was limited until it is guaranteed these products to be harmless. 
Table 3.

Data crossing between answers given to “yes” or “no” questions and the students' attitudes related to Biotechological advances.

\begin{tabular}{|c|c|c|c|c|}
\hline 2nd set of questions & \multicolumn{4}{|c|}{ 1st set of questions biotechnological advance } \\
\hline Eat transgenic food & \multicolumn{2}{|c|}{ Transgenics } & & \\
\hline Restrictions (2) & Disagree & Agree & Total & $p$ value \\
\hline Yes & 48 (59\%) & $41(27 \%)$ & 89 & 0.0001 \\
\hline \multirow[t]{2}{*}{ No } & $33(41 \%)$ & 109 (73\%) & 142 & \\
\hline & 81 & 150 & 231 & \\
\hline \multirow[t]{2}{*}{ Cancer test with genome (5) } & \multicolumn{2}{|c|}{ DNA diagnostics tests } & & \\
\hline & Disagree & Agree & & \\
\hline Yes & $14(54 \%)$ & 145 (79\%) & 159 & 0.0123 \\
\hline \multirow[t]{2}{*}{ No } & $12(46 \%)$ & 39 (21\%) & 51 & \\
\hline & 26 & 184 & 210 & \\
\hline \multirow[t]{2}{*}{ Cancer test with genome (5) } & \multicolumn{2}{|c|}{ Genome project } & & \\
\hline & Disagree & Agree & & \\
\hline Yes & $24(73 \%)$ & $156(82 \%)$ & 180 & 0.2266 \\
\hline \multirow[t]{2}{*}{ No } & $9(27 \%)$ & $33(18 \%)$ & 42 & \\
\hline & 33 & 189 & 222 & \\
\hline & \multicolumn{2}{|c|}{ Genetic vaccines } & & \\
\hline Restrictions to genetic engineered medicine (4) & Disagree & Agree & & \\
\hline Yes & $13(39 \%)$ & 57 (32\%) & 70 & 0.5472 \\
\hline \multirow[t]{3}{*}{ No } & $20(61 \%)$ & $118(68 \%)$ & 138 & \\
\hline & 33 & 175 & 208 & \\
\hline & \multicolumn{2}{|c|}{ Genome project } & & \\
\hline Restrictions to genetic engineered medicine (4) & Disagree & Agree & & \\
\hline Yes & $10(30 \%)$ & 55 (29\%) & 65 & 1.0000 \\
\hline \multirow[t]{2}{*}{ No } & $23(70 \%)$ & $133(71 \%)$ & 156 & \\
\hline & 33 & 188 & 221 & \\
\hline
\end{tabular}

Nevertheless, no other association between questions from the first and the second sets were observed. It seems that students are not confident enough about the concepts we were arguing in relation to the Genome Project and genetic engineering of medicines. These issues are obviously not deeply discussed and debated in the media, and thus students had difficulty in understanding this kind of information. Lack of association was also observed in the joint distribution of the data on detection of cancer test versus Genome Project (item 5, Table 3).

Once again, qualitative analysis helped us to understand students' attitudes. When asked about the Genome Project, they did not know what it really was. Their opinions showed a very basic, narrow-minded and deterministic vision about the subject: that the Genome Project was a fancy technique to fix people with genetic or complex diseases. Consequently, they were unable to correlate Genome Project to their uses. Questions concerning students' opinions about genetic engineering of medicines clearly demonstrated that they did not have any idea about the subject:

Student: By the way, those compounding pharmacies have anything to do with that? [2 seconds] those drugstores where you go and order, and you give the receipt and they make the medicine you need?

Moreover, several students addressed the idea that they were not prepared to understand the Biotechnological improvements that come to society. They also pointed out difficulties with the language used in the media to diffuse the scientific discoveries and scientific knowledge. Most of students' speeches addressed the general idea that scientists speak their own complicated language among themselves, creating confusing theories from very simple hypotheses or scientific product:

Student 4: And they talk in such a language, a very difficult language.

Student 2: And they talk about transgenics...

Student 4: And they speak in a medical language.

Student 1: Scientific language.

Student 4: Yes, scientific, and they talk and one could say "what did he say?" sometimes it's a simple thing, easy, and they make it complicated ... the language ... I think.

Student 3: It has been broadcasted, but their broadcasting is not...

Student 4: The language is very...

Finally, some students clearly showed their inability to "speak Science” (Lemke, 1990), and their difficulties in understanding its basic concepts. Students also indicated that, most of 
the time, they tried to answer the survey and the questions in the interviews with "guesstimations" because they did not really know what they were discussing, especially concerning the Genome Project and genetic engineering of medicines.

\section{Discussion}

Many pieces of information concerning concepts in Biotechnology are present in the daily news as well as in TV shows and movies, such as the use of DNA in criminal justice cases or paternity identification; and human cloning in films and in the press (Jensen et al., 2008), for example, are generally permeated with dangerous ideas and hope (such as finding the cure to some genetic diseases just by concluding the Genome Project). Also, there are contradictory views in the media and in movies in relation to transgenics. All this misleading information usually creates confusion to the population in general. Most films, for example, portray only the negative, the unethical and the immoral aspect of human cloning, while the media points out the fact that it can be used to save lives of people with genetic diseases (Jensen et al., 2008). In spite of that, students have clear opinions on a few matters. The results of the survey show an approval of paternity tests (82\%) and a rejection of human cloning (62\%), indicating that highly covered issues generally follow the dominant and polar "good and bad" ideologies. Thus, our data had internal "positive controls" that helped us analyze the second set of answers.

The results seem to have been influenced by a popular Brazilian soap opera, The Clone, exhibited a few years earlier (2002). It emphasized the negative aspects of cloning, especially human cloning, and showed the possibility of human cloning as something relatively easy to be done. A study using a focal group of high schools students in Brazil analyzed this soap opera corroborating our data indicating that, in fact, few issues in Biotechnology and Molecular Genetics could be debated properly and analyzed by students (Moreira \& Massarani, 2008). Indeed, in the past years in Brazil, popular TV shows have exhibited situations where families discuss the paternity issue, and DNA test is the motif of these TV programs. In addition, news programs frequently show paternity and criminal cases were DNA tests could be applied to solve such cases. Although such discussion has been raised by mass media, scientific issues tend to show too superficially, leading to an oversimplified view of Biotechnological issues (Massarani, 2005). In addition, the media often portrays a bias point of view about scientific discoveries. Such approach does not allow people in general to develop critical thinking about Biotechnology (Jensen, 2008; Lind-Balta, 2006; Harms, 2002).

In this regard, it is clear that students were able to identify some concepts linked to biotechnology and genetic engineering, such as transgenic food and DNA diagnostic tests. However, this ability was restricted to these two themes while, for other topics, the students' ideas were limited to abstract and erroneous conceptions about issues like the Genome Project. Although we did not ask this question explicitly, it was possible to notice from the interviews, that the students acquire their notion on biotechnology information through the media more often than from school classes. It is assumed that school is probably a better place to discuss these issues in-depth; that the educational institution has the most important role in individual development and should provide an environment for the students to develop understanding about new concepts and technologies.
But that is not what can be noticed most of the times schools do not provide adequate infrastructure, classes have much more students than it should, there is not sufficient time to teach what is in the school program, and due to many issues (which will not be discussed here) teachers are not well prepared to work with the new issues concerning concepts in Biotechnology. Other studies corroborate to this view. Ramón et al. (2008) analyzed students' knowledge about Biotechnology issues, and Šorgo and Dolinšek (2009) focused his work on teachers' knowledge about these topics. Both articles identified the need of discussing the new issues in Genetics and Molecular Biology in school, and teachers' lack of fluency concerning Biotechnology issues. Our data endorse the conclusions of these previous publications. Possibly, the introduction of more Genetics and Molecular Biology issues in school books could help students and teachers cope with this new area.

Some basic concepts presented to students in the first year of high school are necessary for the understanding of Genetics and Evolution. Also, other Biotechnological issues need to be discussed in the third year. Assuming that the student learns from what he knows about, it is necessary to present and discuss objectively students' difficulties about the concepts in Biotechnology. Such difficulties are well exemplified in the student's speech: "Can we express ourselves sincerely? ... we answered based on what we could deduce here." It is clear that they have never discussed the new Biotechnologies properly. So, they have no way of having concepts in Biotechnology settled.

Unfortunately, the learning-teaching process is still based on outdated educational books and mostly solely on lecture classes, which tends to lead to a shallow notion of important Biotechnological concepts. It would, therefore, be a difficult task for these students to behave as critical and active citizens in a constantly changing society.

It was also noticed that students often mentioned that scientific language sounds unfamiliar. This occurs because they have not been in contact with scientific terminology. Thus, they cannot understand some important relationships between some Biotechnological advances, such as the Genome Project, genetically engineered medicines and Genetic Vaccines. The superficial level of students' knowledge in such matters became clear as they get in touch with the scientific language. It is properly exemplified when a student expresses their misconception about genetically engineered medicine, making it a synonym of designed-medicines in drugstores.

Teachers were questioned about their sources of information for class planning (Xavier et al., 2006) and it was verified that their major source was the school textbook, which is used by students for classes as well as for studying for tests. The textbook, as told previously, does not present up-to-date and contextualized contents.

Finally, we understand that our approach have limitations since we studied only three schools, although in different locations in Rio de Janeiro state. However, it is difficult to extrapolate our results to other states in Brazil and even other municipalities in Rio. Also, we tried to better comprehend differences between public and private schools and, in our hands, we did not capture such differences that could also be accounted for small sample size we used specially concerning the number of private students enrolled. Nevertheless, our data are consistent since we used different methodologies and have been corroborated by others in Brazil (Massarani, 2005). 
Based on the results, we conclude that high school students do not have proper contact with biotechnology issues at school. Although they may get into contact with biotechnology advances through TV shows or the media, they still demonstrate misconceptions. The scientific language is a barrier because of the lack of an in-depth discussion about scientific discoveries in biotechnology. Anyway, the results presented herein are consistent with the lack of discussion of biotechnological issues in school classes. Therefore, changes show to be not only urgent but also extremely important.

\section{REFERENCES}

Araújo-Jorge, T., Cardona, T., Mendes, C., Henriques-Pons, A., Meirelles, R., Coutinho, C., Aguiar, L., Meirelles, M. N., Castro, S., Barbosa, H., \& Luz, M. (2004). Microscopy images as interactive tools in cell modeling and cell biology education. Cell Biology Education, 3, 99-110. doi:10.1187/cbe.03-08-0010

Cavanagh, H., Hood, J., \& Wilkinson, J. (2005). Riverina high school students' views of biotechnology. Electronic Journal of Biotechnology, 8, 121-127. doi:10.2225/vol8-issue2-fulltext-1

Dawson, V., \& Schibeci, R. (2003). Western Australian high school students' attitudes towards biotechnlogy processes. Journal of Biotechological Education, 38, 7-11. doi:10.1080/00219266.2003.9655889

De Mattos, J. C. P., Dantas, F. J. S., Caldeiras-de-Araújo, A., \& Moraes, M. O. (2004). Agarose gel eletrophoresis system in the classroom. Biochemistry and Molecular Biology Education, 32, 254-257. doi:10.1002/bmb.2004.494032040382

Eyck, T. T. (2005). The media and public opinion on genetics and biotechnology: Mirrors, windows, or walls? Public Understanding of Science, 14, 305-316. doi:10.1177/0963662505052888

Gelbart, H., \& Yarden, A. (2006). Learning genetics through an authen- tic research simulation in bioinformatics. Journal of Biological Education, 40, 107-112. doi:10.1080/00219266.2006.9656026

Harms, U. (2002). Biotechnology education in Schools. Electronic Journal of Biotechnology, 5, 205-211. doi:10.2225/vol5-issue3-fulltext-i03

Jensen, E. (2008). The Dao of human cloning: Utopian/dystopian hype in the British press and popular films. Public Understanding of Science, 17, 123-143. doi:10.1177/0963662506065874

Lemke, J. L. (1990). Talking science: Language, learning and values. Stanford: Ablesc/JAI Publishing Corporation.

Lind-Balta, E. (2006). Using literature and innovative assessments to ignite interest and cultivate critical thinking skills in an undergraduate neuroscience course. Life Sciences Education, 5, 167-174. doi:10.1187/cbe.05-08-0108

Massarani, L., \& Moreira, I. C. (2008). Not in our genes! Um estudo de caso com jovens do ensino médio no Rio de Janeiro. Alexandria Revista de Educação em Ciência e Tecnologia, 1, 51-76.

Massarani, L., \& Moreira, I. C. (2005). Attitudes towards genetics: A case study among Brazilian high school students. Public Understanding of Science, 14, 201-212. doi:10.1177/0963662505050992

Peters, M. W., Smith, M. F., \& Smith G. W. (2002). Use of critical interactive thinking exercises in teaching reproductive physiology to undergraduate students. Journal of Animal Science, 80, 862-865.

Peters, V., \& Vissers, G. (2004). A simple classification model for debriefing simulation games. Simulation and Gaming, 35, 20-83. doi: $10.1177 / 1046878103253719$

Ramón, D., Diamante, A., \& Calvo, M. D. (2008). Food biotechnlogy and education. Eletronic Journal of Biotechnology, 11, 1-5.

Sorgo, A., \& Ambrozic-Dolinsek, J. (2009). The relationship among knowledge of, attitudes toward and acceptance of genetically modified organisms (GMOs) among Slovenian teachers. Electronic Journal of Biotechnology, 12, 1-13. doi:10.2225/vol12-issue4-fulltext-1

Xavier, M. C. F., Freire, A. S., \& Moraes, M. O. (2006). A nova (moderna) biologia e a genética nos livros didáticos de biologia no ensino médio. Ciência e Educação, 12, 275-289. 